\title{
Modulation of Cardiac Connexin-43 by Omega-3 Fatty Acid Ethyl- Ester Supplementation Demonstrated in Spontaneously Diabetic Rats
}

\author{
J. RADOSINSKA ${ }^{1,2}$, L. H. KURAHARA ${ }^{3}$, K. HIRAISHI ${ }^{3}$, C. VICZENCZOVA ${ }^{2}$, \\ T. EGAN BENOVA ${ }^{2}$, B. SZEIFFOVA BACOVA ${ }^{2}$, V. DOSENKO ${ }^{4}$, J. NAVAROVA $^{5}$, \\ B. OBSITNIK ${ }^{6}$, I. IMANAGA ${ }^{3}$, T. SOUKUP ${ }^{7}$, N. TRIBULOVA ${ }^{2}$
}

${ }^{1}$ Institute of Physiology, Faculty of Medicine, Comenius University, Bratislava, Slovakia, ${ }^{2}$ Institute for Heart Research, Slovak Academy of Sciences, Bratislava, Slovakia, ${ }^{3}$ Department of Physiology, Fukuoka University Medical School, Fukuoka, Japan, ${ }^{4}$ Bogomoletz Institute of Physiology, Kyiv, Ukraine, ${ }^{5}$ Institute of Experimental Pharmacology and Toxicology, Slovak Academy of Sciences, Bratislava, Slovakia, ${ }^{6}$ St Elisabeth Institute of Oncology, Bratislava, Slovakia, ${ }^{7}$ Institute of Physiology, Czech Academy of Sciences, Prague, Czech Republic

Received May 21, 2015

Accepted September 30, 2015

On-line October 8, 2015

\section{Summary}

Previous data suggest that type 1 diabetes mellitus leads to the deterioration of myocardial intercellular communication mediated by connexin-43 (Cx43) channels. We therefore aimed to explore Cx43, PKC signaling and ultrastructure in non-treated and omega-3 fatty acid (omega-3) treated spontaneously diabetic Goto-Kakizaki (GK) rats considered as type 2 diabetes model. Four-week-old GK and non-diabetic Wistar-Clea rats were fed omega-3 (200 mg/kg/day) for 2 months and compared with untreated rats. Real-time PCR and immunoblotting were performed to determine Cx43, PKC-epsilon and PKC-delta expression. In situ $\mathrm{C} \times 43$ was examined by immunohistochemistry and subcellular alterations by electron microscopy. Omega-3 intake reduced blood glucose, triglycerides, and cholesterol in diabetic rats and this was associated with improved integrity of cardiomyocytes and capillaries in the heart. Myocardial Cx43 mRNA and protein levels were higher in diabetic versus non-diabetic rats and were further enhanced by omega- 3 . The ratio of phosphorylated (functional) to non-phosphorylated Cx43 was lower in diabetic compared to non-diabetic rats but was increased by omega-3, in part due to up-regulation of PKC-epsilon. In addition, pro-apoptotic PKC-delta expression was decreased. In conclusion, spontaneously diabetic rats at an early stage of disease benefit from omega- 3 intake due to its hypoglycemic effect, upregulation of myocardial Cx43, and preservation of cardiovascular ultrastructure. These findings indicates that supplementation of omega-3 may be beneficial also in the management of diabetes in humans.

\section{Key words}

Diabetes • Omega-3 fatty acids • Cardiac connexin-43 - PKC • Ultrastructure

\section{Corresponding author}

N. Tribulová, Institute for Heart Research, Slovak Academy of Sciences, 84005 Bratislava, Dúbravská cesta 9, POBox 104. Fax: 00421254776637. E-mail: narcisa.tribulova@savba.sk

\section{Introduction}

Type 2 diabetes mellitus (T2DM), the most common form of diabetes, has reached pandemic proportions worldwide. T2DM is a progressive metabolic disorder in which glucose tolerance is impaired due to defects in insulin secretion and/or insulin action. Patients with T2DM are recognized to have an increased risk of cardiovascular morbidity and mortality (Julien 1997). It should be noted that hyperglycemia deteriorates endogenous cardioprotection (Zálešák et al. 2015). It is also clear that dietary components have significant and clinically relevant effects on blood glucose modulation. Nutritional regulation of blood glucose levels is therefore 
a strategic target in the prevention and management of T2DM.

Omega-3 polyunsaturated fatty acids (omega-3) are considered useful agents in the prevention of diabetes or at least in the reduction of insulin resistance (Fedor and Kelley 2009, Villarroya et al. 2014). This is in part due to their modulation of membrane fluidity (Stillwell and Wassall 2003) and inhibition of dipeptidyl peptidase-4 (Mitašíková et al. 2008), an enzyme that breaks down glucagon-like peptide (a crucial hormone regulating glucose homeostasis). Omega-3 supplementation also improves clinical outcomes of heart failure and mortality, including patients with diabetes (Marchioli et al. 2007, Kazemian et al. 2012, Poole et al. 2013). Importantly, lower plasma and/or red blood cell level of omega-3 was reported in patients suffering from cardiovascular diseases (von Schacky and Harris 2007) and diabetes (Sertoglu et al. 2014) as well as in rat models (Bačová et al. 2013) including T2DM rat hearts (Hou et al. 2012).

Over the past 30 years, the mechanisms by which omega-3 can improve cardiovascular health, namely dyslipidemias, anti-inflammatory, antiaggregatory, and anti-arrhythmic effects as well as an improvement in endothelial function, have been investigated extensively (Deckelbaum et al. 2006, Zuliani et al. 2009, Cottin et al. 2011, Villarroya et al. 2014, Soukup 2014). Interestingly, recent data indicate that inflammation can be targeted to treat or reduce T2DM risk (Jayashree et al. 2014) and that omega-3 can preserve the function of some enzymes during inflammation (Mézešová et al. 2013). Moreover, as a ligand of the transcription factor peroxisome proliferator-activated receptor (PPAR), omega-3 can increase glucose uptake and improve insulin sensitivity similarly to PPAR agonists (thiazolidinediones, insulinsensitizing drugs) that have been applied for the treatment of T2DM (Seok and Cha 2013). PPAR agonists have been shown to prevent the onset of T2DM in Zucker diabetic fatty rats (Bergeron et al. 2006). Our most recent findings (Zhukovska et al. 2014) indicate that rats with T1DM benefit from omega-3 intake via an improvement of cardiac output, which was partially attributed to the attenuation of myocardial connexin-43 (Cx43) abnormalities. Intercellular $\mathrm{Cx} 43$ channels are essential for direct communication between cardiomyocytes, ensuring action potential and molecular signal propagation resulting in synchronized heart function (Fontes et al. 2012, Tribulová et al. 2005, 2008, 2010).
We have previously shown that upregulation of PKC-epsilon signaling associated with hyperphosphorylation of $\mathrm{Cx} 43$ led to increased $\mathrm{Cx} 43$ channel resistance and decreased myocardial conduction velocity in T1DM rats (Lin et al. 2006, 2008, Mitašíková et al. 2009). These changes, in addition to potassium channel alterations (Shimoni and Liu 2003), may be behind prolongation of the QRS and QT interval, thereby affecting heart function in T1DM (Howarth et al. 2008). However, data concerning myocardial intercellular communication in T2DM are lacking. We hypothesized that both T2DM and omega-3 may affect $\mathrm{Cx} 43$ gene transcription and/or posttranslational levels of $\mathrm{Cx} 43$ and particularly its functional phosphorylated status. To verify our hypothesis, we used the Goto-Kakizaki (GK) rat strain, which is considered one of the best-characterized animal models for the study of spontaneous T2DM (Wang et al. 2013). Focusing on the possible prevention of T2DM, we aimed to investigate the efficacy of a highly purified omega- 3 fatty acid ethyl ester (Omacor).

\section{Materials and Methods}

\section{Animal model}

All experiments were performed in accordance with the Guide for the Care and Use of Laboratory Animals published by the National Institutes of Health (publication 85-23, revised in 1996) and approved by the Animal Research and Care Committees of Fukuoka University and the Institute for Heart Research regarding the handling of experimental animals.

Experiments were conducted on male 4-weekold spontaneously diabetic Goto-Kakizaki (GK) rats and age-matched non-diabetic Wistar-Clea (WC) rats. Animals were divided into four groups: non-diabetic untreated rats (WCc, $\mathrm{n}=8)$, diabetic untreated rats $(\mathrm{GKc}$, $\mathrm{n}=8$ ), non-diabetic rats treated with Omacor (WCo3, $\mathrm{n}=8)$, and diabetic rats treated with Omacor $(\mathrm{GKo3}, \mathrm{n}=8)$. Untreated rats were fed standard laboratory chow only, while treated rats were supplemented in addition with Omacor (docosahexaenoic acid [DHA] + eicosapentaenoic acid [EPA] ethylesters, Pronova BioPharma, Norway, $40 \mathrm{mg} / 100 \mathrm{~g}$ body weight/day for 2 months. Calculated volume of Omacor was administered per os. At the end of the experiments, body weight, blood glucose, plasma triacylglycerols (TAG), cholesterol and alpha-N-acetylgalactoaminidase (NAGA) were recorded. NAGA was analyzed because diabetes is known to be related to oxidative stress, which may be associated with 
release of NAGA due to lysosomal lipid peroxidation (Kramer et al. 2006). The animals were anesthetized by exposure to ethyl-ether, their chests were opened and excised hearts were quenched in ice-cold saline solution to stop them from beating. The weights of the whole heart and left ventricle were quickly recorded. Left ventricular heart tissue was then snap-frozen in liquid nitrogen and stored at $-80^{\circ} \mathrm{C}$ until use.

Real-time PCR was used to determine $\mathrm{Cx} 43$ mRNA expression and immunoblotting was used to determine Cx43, PKC-epsilon and PKC-delta protein expression. Transmural cryostat sections of left ventricular tissue were used for immunostaining to detect in situ $\mathrm{Cx} 43$ myocardial localization. Small blocks $\left(1-2 \mathrm{~mm}^{3}\right)$ of nonfrozen left ventricular tissue were processed for transmission electron microscopy examination.

\section{Examination of the heart ultrastructure}

Ventricular tissue blocks ( $\mathrm{n}=5$ per heart) were fixed in $2.5 \%$ glutaraldehyde buffered with $100 \mathrm{mmol}^{-1^{-1}}$ sodium cacodylate for $3 \mathrm{~h}$ at $4{ }^{\circ} \mathrm{C}$, washed in buffer and subsequently post-fixed in $1 \% \mathrm{OsO}_{4}$, dehydrated via ethanol series, infiltrated by propylene oxide and embedded in Epon 812, as described previously (Lin et al. 2008). Semi-thin sections $(1 \mu \mathrm{m})$ were cut and stained with toluidine blue for light microscopic examination in order to select a representative area of the tissue sample for ultrathin sectioning. Ultrathin sections were stained with uranyl acetate and lead citrate. The ultrastructure was examined using a transmission electron microscope (BS 500, Tesla, Brno, Czech Republic).

\section{In situ immunofluorescence labeling of myocardial Cx43}

Left ventricular cryostat sections ( $\mathrm{n}=5$ per heart)

were exposed to the mouse monoclonal anti-Cx43 antibody (Chemicon International, Inc.) at a dilution of 1:200 for $1 \mathrm{~h}$ at room temperature, followed by secondary FITC-conjugated goat anti-mouse antibody, as described previously (Lin et al. 2008). Specificity of the immunoreaction was verified by incubation of the slices without primary antibody. Immunostained sections were examined using a fluorescence microscope (Axiostar, Carl Zeiss, Jena, Germany). Quantitative analysis was carried out as follows: a $2000 \mu \mathrm{m}^{2}$ square image was imported into NIH Image $J$ software for analysis. The threshold for creating a binary image for counting was kept constant between images and was set to ensure that spots that represented $\mathrm{Cx} 43$ labeling would be counted without interference from background and the number of spots above background was counted automatically. The minimum detectable plaque size was $1 \mu \mathrm{m}^{2}$. Four fields were analyzed for each set of measurements. The number of labeled gap junctions measured in each field was plotted as a frequency histogram.

\section{Real-time PCR for connexin-43-mRNA assay}

RNA isolation and reverse transcription were performed as described previously (Bačová et al. 2012). The obtained single-chain DNA was used for real-time PCR. Amplification was performed in $10 \mu \mathrm{l}$ of SYBR

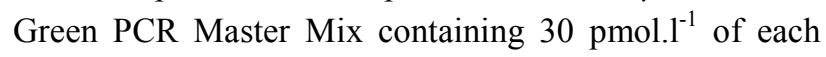
primer. For amplification of GJP43 gene and beta-actin (the housekeeping gene was not reported to be changed in $\mathrm{DM})$, gene fragments of the following primers were used to determine Cx43-mRNA level: GJP43, sense 5'-TCC TTG GTG TCT CTC GCT TT-3', antisense 5'-GAG CAG CCA TTG AAG TAG GC-3'; and beta-actin, sense 5'-TCA TCA CTA TCG GCA ATG AGC-3', antisense 5'-GGC CAG GAT AGA GCC ACC A-3'. Sample volume was adjusted to $20 \mu \mathrm{l}$ with deionized water. Amplification was performed as previously described (Zhukovska et al. 2014). The CT (cycle threshold) was defined as the number of cycles required for the fluorescence signal to exceed the detection threshold. We calculated the expression of the target gene relative to the housekeeping gene as the difference between the CT values of the two genes.

Immunoblot analysis of connexin-43 and PKC expression For $\mathrm{Cx} 43$ and overall PKC analysis, left ventricular frozen tissue was powdered in liquid nitrogen and solubilized in SB20 solution (20\% SDS, $10 \mathrm{mmol}^{\mathrm{I}^{-1}}$ EDTA, 0.1 mol. $^{-1}$ TRIS, pH 6.8) by a sonicator (UP $100 \mathrm{H}$, Hielscher, Germany). In order to differentiate PKC expression in the soluble and particulate fractions, left ventricular tissue was homogenized in an ice-cold homogenization buffer containing $20 \mathrm{mmol}^{-1} \mathrm{l}^{-1}$ Tris-HCl, 250 mmol..$^{-1}$ sucrose, 1.0 mmol..$^{-1}$ EGTA, 1.0 mmol. ${ }^{-1}$ dithiothreitol (DTT), $1.0 \mathrm{mmol}^{-1} \mathrm{l}^{-1}$ phenylmethylsulfonylfluoride (PMSF), and 0.5 mmol. $\mathrm{I}^{-1}$ sodium orthovanadate (resulting $\mathrm{pH}$ 7.4) using a Teflon glass homogenizer as previously described in Bačová et al. (2012). To determine Cx43, PKC-epsilon, and PKC-delta protein expression, membranes were incubated with the following primary rabbit polyclonal antibodies: $\mathrm{Cx} 43$ (C 6219, Sigma-Aldrich, dilution 1:2000), PKC-epsilon (C-15, sc-214, Santa Cruz Biotechnology Inc., dilution 1:1000), and PKC-delta (C-17, sc-213, Santa Cruz 
Biotechnology Inc., dilution 1:1000). Overnight incubation at $4{ }^{\circ} \mathrm{C}$ was followed by further incubation with a secondary donkey antibody (peroxidase-labeled antirabbit immunoglobulin, Amersham Biosciences, dilution 1:2000) for $1 \mathrm{~h}$ at room temperature. Antibody binding was detected with the enhanced chemilumi- nescence method. The optical density of individual bands was analyzed using PCBAS 2.08e software and normalized to GAPDH or actin (particulate fraction) as an internal loading control. The expression of both proteins is not altered in the diabetic heart as verified by our studies and available literature.
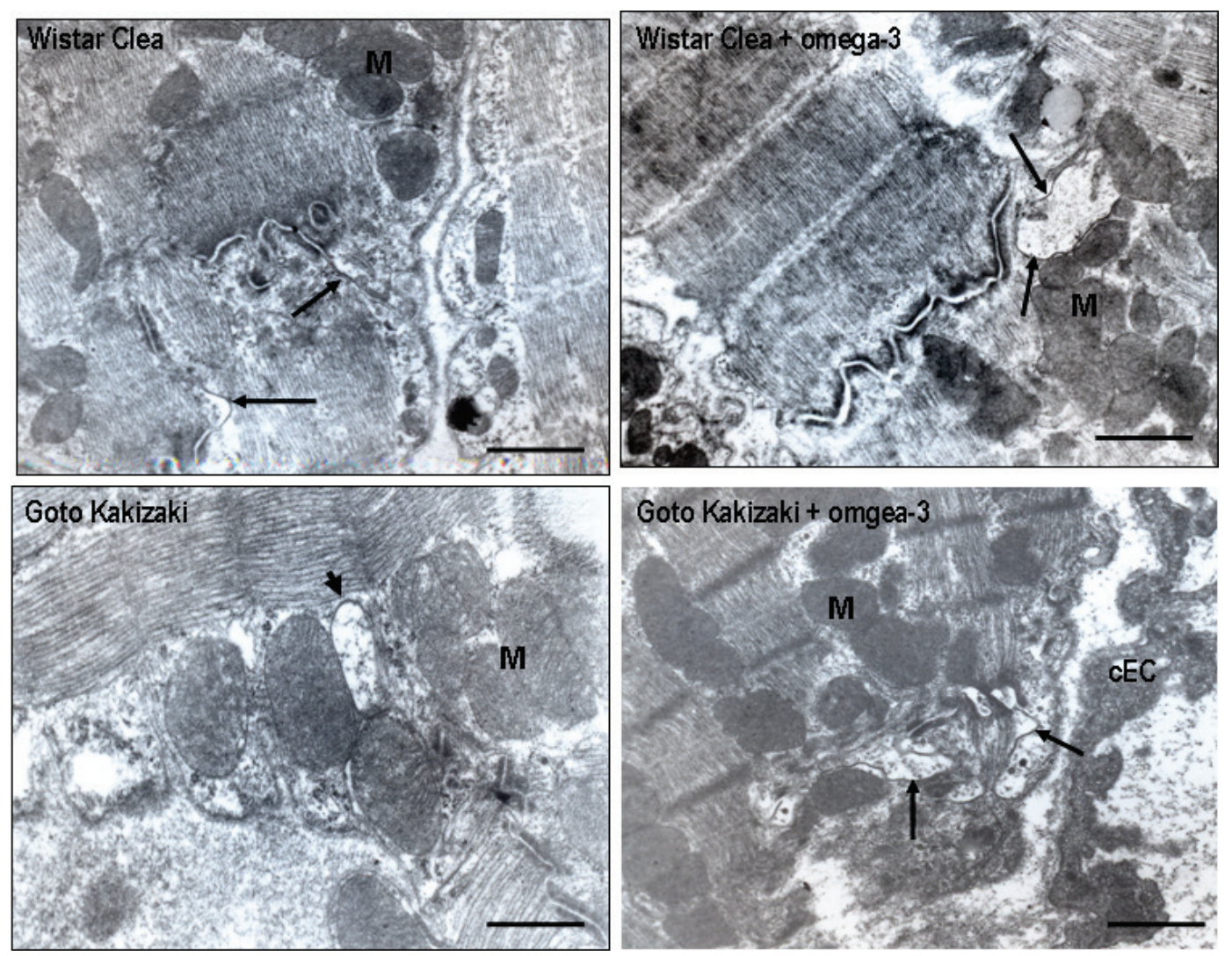

Fig. 1. Normal ultrastructure of the healthy rat heart as indicated by electron-dense mitochondria $(M)$ and preserved integrity of the cell membrane and gap junctions (arrows) located predominantly at the intercalated disc. This pattern was also seen after treatment with omega-3, but longer gap junctions were often observed. In addition to the normal pattern, a population of structurally altered cardiomyocytes with injured mitochondria (M) and shorter intercalated disc-related gap junctions (arrow) was observed in Goto-Kakizaki (GK) rat hearts. Apparent preservation of mitochondrial ultrastructure and a higher number of longer gap junctions were observed after treatment of diabetic rats with omega-3. Scale bar, $1 \mu \mathrm{m}$.

Table 1. Principal characteristics of the experimental animals.

\begin{tabular}{lllll}
\hline & WCc & WCo3 & GKc & GKo3 \\
\hline$B W(g)$ & $432 \pm 29$ & $429 \pm 17$ & $353 \pm 20^{*}$ & $342 \pm 14$ \\
$H W(g)$ & $1.14 \pm 0.09$ & $1.11 \pm 0.07$ & $0.98 \pm 0.04^{*}$ & $1.03 \pm 0.02$ \\
$L V W(g)$ & $0.81 \pm 0.08$ & $0.79 \pm 0.06$ & $0.68 \pm 0.03^{*}$ & $0.69 \pm 0.04$ \\
$L V W / B W(m g / g)$ & $1.85 \pm 0.09$ & $1.82 \pm 0.10$ & $1.95 \pm 0.03^{*}$ & $1.98 \pm 0.08$ \\
$B G\left(m m o l . l^{-1}\right)$ & $9.02 \pm 2.53$ & $8.08 \pm 2.37$ & $26.57 \pm 3.73^{*}$ & $21.57 \pm 4.30^{\#}$ \\
$T G\left(\right.$ mol. $\left.l^{-1}\right)$ & $0.54 \pm 0.14$ & $0.70 \pm 0.22$ & $1.21 \pm 0.29^{*}$ & $0.9 \pm 0.27^{\#}$ \\
$C H\left(\right.$ mmol. $\left.l^{-1}\right)$ & $1.34 \pm 0.19$ & $1.57 \pm 0.22$ & $2.15 \pm 0.07^{*}$ & $1.99 \pm 0.16^{\#}$ \\
$N A G A$ (specific activity) & $0.106 \pm 0.028$ & $0.118 \pm 0.043$ & $0.164 \pm 0.058^{*}$ & $0.155 \pm 0.030$ \\
\hline
\end{tabular}

BW, body weight; HW, heart weight; LVW, left ventricular weight; BG, blood glucose; TG, triacylglycerols; CH, cholesterol; NAGA, alpha-Nacetylgalacto-saminidase. Data are means \pm SD. * $p<0.05$ compared with the WCc group, \# $p<0.05$ compared with the GKc group. 


\section{Statistical analysis}

Comparison between two groups was performed using the unpaired $t$ test. The data are expressed as mean \pm standard deviation (SD) and values were considered to differ significantly at $\mathrm{P}<0.05$. Statistical significance of gap junction size was evaluated using Dunnett's test for multiple comparisons. Data are expressed as mean \pm standard error (SE). $\mathrm{P}<0.05$ values were considered statistically significant.
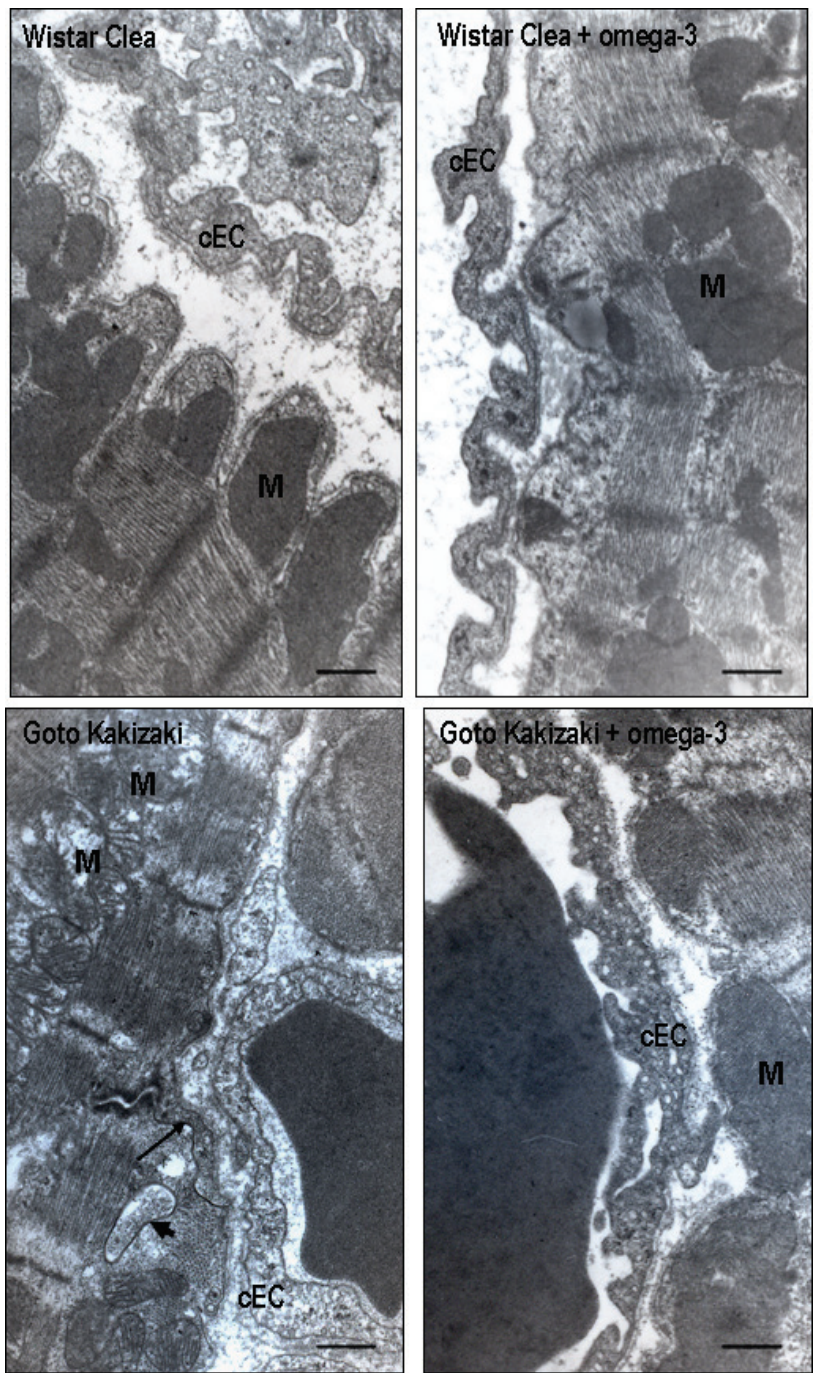

Fig. 2. The normal appearance of capillary endothelial cells (CEC) and mitochondria (M) is seen in healthy rat hearts. Note the high number of pinocytic vesicles. In addition to the normal pattern, edematous endothelial cells with reduced pinocytic activity were observed in Goto-Kakizaki rat hearts. Moreover, the image shows the presence of annular internalized gap junction (arrow) and electron lucent mitochondria in the diabetic rat heart. Omega-3 supplementation was associated with preserved ultrastructure of both CEC containing numerous pinocytic vesicles and cardiomyocytes exhibiting tightly packed mitochondria and longer gap junctions (arrows). Scale bar, $1 \mu \mathrm{m}$.

\section{Results}

\section{Principal characteristics of the experimental animals}

As summarized in Table 1, the diabetic rats exhibited significantly higher blood glucose levels compared to non-diabetic rats. Furthermore, GK rats were characterized by lower body, heart and left ventricular weights, as well as by higher left ventricle-to-body weight ratio, higher serum TAG and cholesterol levels and NAGA specific activity. Omega-3 supplementation of diabetic rats reduced blood glucose levels, serum TAG and cholesterol. Omega-3 intake affected neither the body, heart and left ventricular weights nor left ventricleto-body weight ratio and NAGA specific activity in serum of diabetic rats.

\section{Myocardial ultrastructure and subcellular localization of} gap junctions

Unlike the preserved integrity of cardiomyocytes and capillaries observed in healthy Wistar Clea rats, left ventricular tissue from diabetic rats was characterized by variability and heterogeneity of subcellular alterations (Figs 1 and 2). Although the majority of cardiomyocytes exhibited normal ultrastructure and junctions (not shown), some cardiomyocytes in GK rats exhibited ischemia-like intracellular edema, electro-lucent mitochondria, and shorter or internalized gap junctions (Figs 1 and 2). Such cardiomyocytes were usually in the vicinity of altered capillaries exhibiting edematous endothelial cells with reduced pinocytic activity (Fig. 2). Healthy rat heart cardiomyocytes exhibited conventional localization of gap junctions predominantly at the intercalated discs (end-to-end type) in the vicinity of adhesive fascia adherens junctions. Laterally located gap junctions (side-to-side type) in the vicinity of adhesive desmosome junctions were rarely observed. Unlike this pattern, lateral side-to-side type junctions were more frequently observed in diabetic rat hearts. Treatment with omega-3 (Figs 1 and 2) resulted in preservation of mitochondrial and cardiomyocyte ultrastructure as well as improved integrity of capillary endothelial cells in diabetic rat hearts. Additionally, a greater number of longer gap junctions was observed in both omega 3-treated groups.

\section{In situ immunodetection of myocardial Cx43}

A conventional, uniform spatial distribution of Cx43-positive gap junctions was observed in hearts of non-diabetic rats by in situ immunofluorescence (Fig. 3a). 

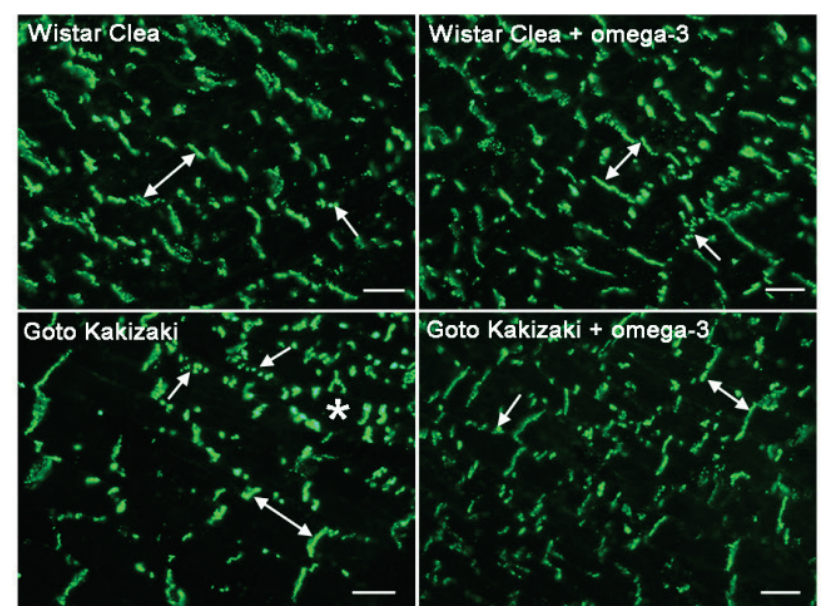

Fig. 3a. Immuno-labeling of connexin-43 (Cx43) in the left ventricles of untreated and omega-3-treated Wistar-Clea (WC) and Goto-Kakizaki (GK) rats. Note the conventional distribution of Cx43-positive gap junctions predominantly at the intercalated discs (double arrows) and sporadically on lateral surfaces (arrows) in both groups of WC rats. In contrast, an abnormal pattern of Cx43-positive gap junction distribution is observed in GK rat hearts, i.e. organized and disorganized localization (asterisk) of Cx43-positive gap junctions. Treatment of diabetic rats with omega-3 appeared to decrease abnormal Cx43 distribution. Scale bars, $10 \mu \mathrm{m}$.

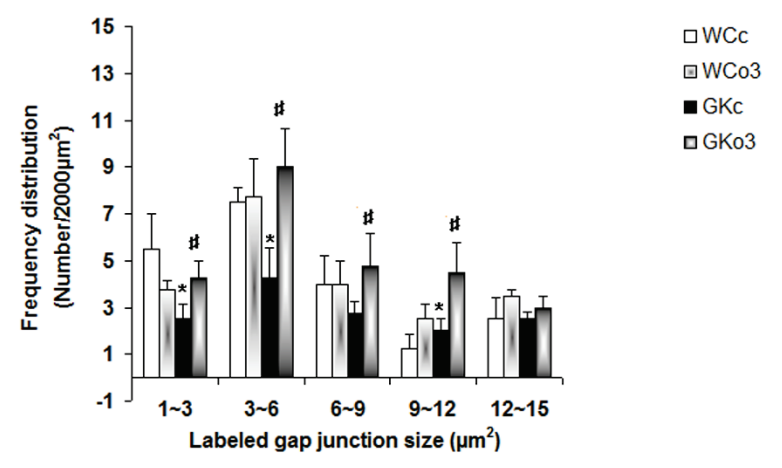

Fig. 3b. Quantitative image analysis of the size of Cx43positively labeled gap junctions. Four fields were analyzed for each set of measurements. The number of labeled gap junctions measured in each field was plotted as a frequency histogram. The mean, standard error of the mean were calculated using Dunnett's test for multiple comparisons. $* p<0.05$ compared with the WCc group, \# p<0.05 compared with the GKc group.

This normal pattern of $\mathrm{Cx} 43$ distribution, showing dominant end-to-end-type localization at the intercalated disc and rare side-to-side-type Cx43-positive gap junctions, was present in healthy rats regardless of omega-3 treatment. In contrast, the diabetic rat hearts were characterized by non-uniform spatial distribution of Cx43-positive gap junctions, i.e. in addition to the normal pattern, areas with apparently disorganized localization and higher prevalence of side-to-side Cx43-positive gap junctions were detected. This abnormal distribution of $\mathrm{Cx} 43$ in diabetic rat cardiomyocytes was markedly attenuated by treatment with omega-3 (Fig. 3a). Moreover, quantitative image analysis revealed that the size of Cx43-positive gap junctions was significantly reduced in diabetic compared to non-diabetic rat heart left ventricles while this parameter increased in omega-3-treated rats (Fig. 3b).

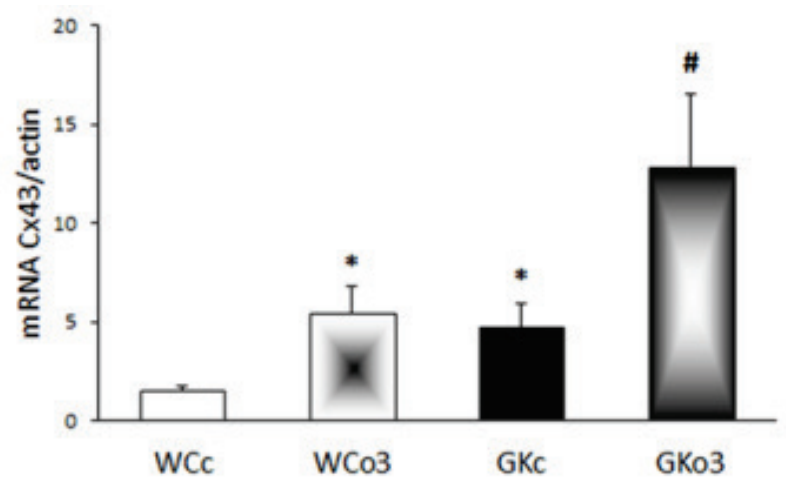

Fig. 4. Connexin-43 (Cx43) mRNA expression normalized to beta-actin (actin) in the left ventricles of untreated and omega-3 treated Wistar-Clea (WC) and Goto-Kakizaki (GK) rat hearts. WCc, untreated WC; WCo3, WC treated with omega-3; GKc, untreated GK; GKo3, GK treated with omega-3. The results are the mean $\pm S D$ of 8 hearts per group. $* p<0.05$ compared with the WCc group, \# $p<0.05$ compared with the GKc group.

\section{Myocardial Cx43 mRNA levels and Cx43 protein expression}

Myocardial Cx43 mRNA gene transcription was higher in diabetic compared to non-diabetic rats and omega-3 intake significantly increased $\mathrm{Cx} 43$ mRNA expression both in diabetic rats and to a minor extent in non-diabetic rats (Fig. 4). Immunoblot analysis revealed three forms of $\mathrm{Cx} 43$ corresponding to two phosphorylated (P1- and $\mathrm{P} 2-\mathrm{Cx} 43$ ) and one nonphosphorylated ( $\mathrm{P} 0-\mathrm{Cx} 43)$ form in all examined rats (Fig. 5a). Compared to non-diabetic rats, the expression of total $\mathrm{Cx} 43$ as well as its phosphorylated forms was significantly increased in diabetic rats. Omega-3 supplementation further enhanced levels of total $\mathrm{Cx} 43$ protein and its phosphorylated forms (Figs $5 \mathrm{~b}$ and $5 \mathrm{c}$ ). However, compared to non-diabetic rats, the ratio of phosphorylated $\mathrm{Cx} 43$ to total $\mathrm{Cx} 43$ was significantly lower in diabetic rats and intake of omega- 3 increased this ratio (Fig. 5d).

\section{Myocardial expression of $P K C \varepsilon$ and $P K C \delta$}

Compared to non-diabetic rat hearts, the total expression levels of PKC $\varepsilon$ and PKC $\delta$ were increased in the diabetic group (Figs 6a and 7a). Myocardial total PKCE was further increased upon omega-3 
(a)
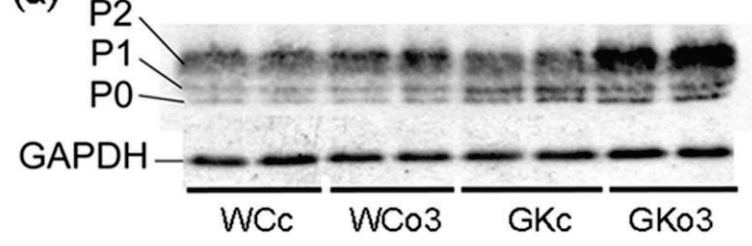

(b)

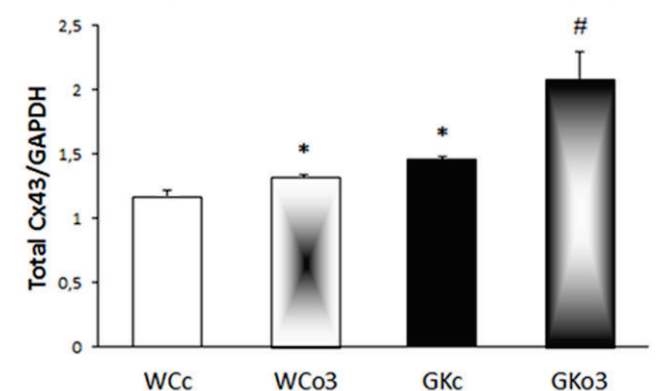

(c)

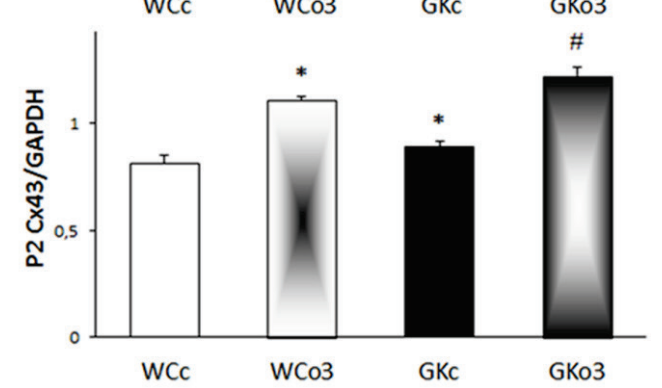

(d)

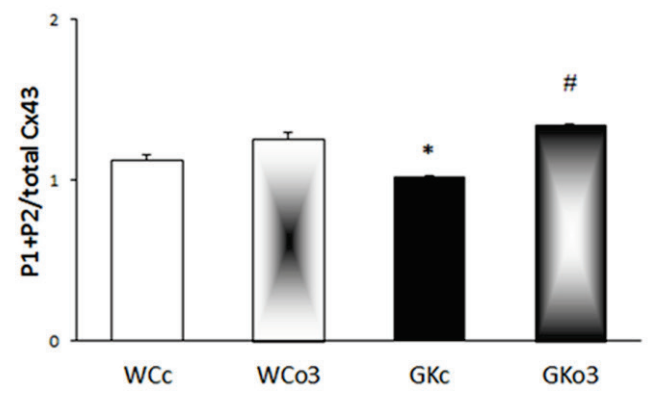

Fig. 5. Representative immunoblot showing 3 forms of connexin-43 (Cx43) (a) and densitometric quantification of total Cx43 expression (b), its highly phosphorylated form (c) and the ratio of both phosphorylated forms of Cx43 to total Cx43 (d) normalized to GAPDH in the left ventricles of untreated and omega-3-treated Wistar-Clea (WC) and Goto-Kakizaki (GK) rat hearts. P0, unphosphorylated form of Cx43; $\mathrm{P} 1$, partially phosphorylated Cx43, P2, highly phosphorylated Cx43. WCC, untreated WC; WCO3, WC treated with omega-3; GKc, untreated GK; GKo3, GK treated with omega-3. The results are the mean \pm SD of 8 hearts per group. * $\mathrm{p}<0.05$ compared with the WCC group, \# $p<0.05$ with the GKc group.

supplementation in both the diabetic and non-diabetic groups (Fig. 6a). In contrast, the increase of myocardial total $\mathrm{PKC} \delta$ in the diabetic group was significantly suppressed by omega-3 treatment (Fig. 7a). Examination of particulate and soluble fractions of myocardial PKC revealed that expression of particulate PKC $\varepsilon$ (Fig. 6b) was higher in diabetic than non-diabetic rats and was increased by omega- 3 intake in both groups, which was associated with a decrease in soluble PKCE (Fig. 6c).
Compared to non-diabetic rats, the level of particulate PKC $\delta$ (Fig. 7b) was higher in diabetic rats and was normalized by omega-3 intake. Soluble PKC $\delta$ (Fig. 7c) was higher in diabetic than non-diabetic rats and omega-3 intake decreased soluble PKC $\delta$ in both groups.

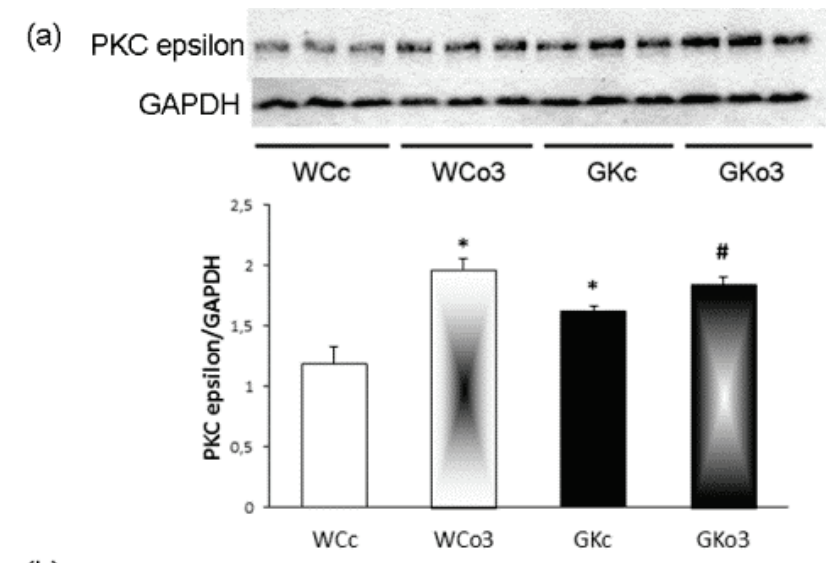

(b)

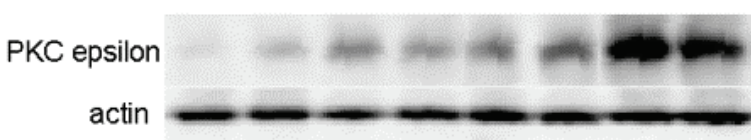

(c)
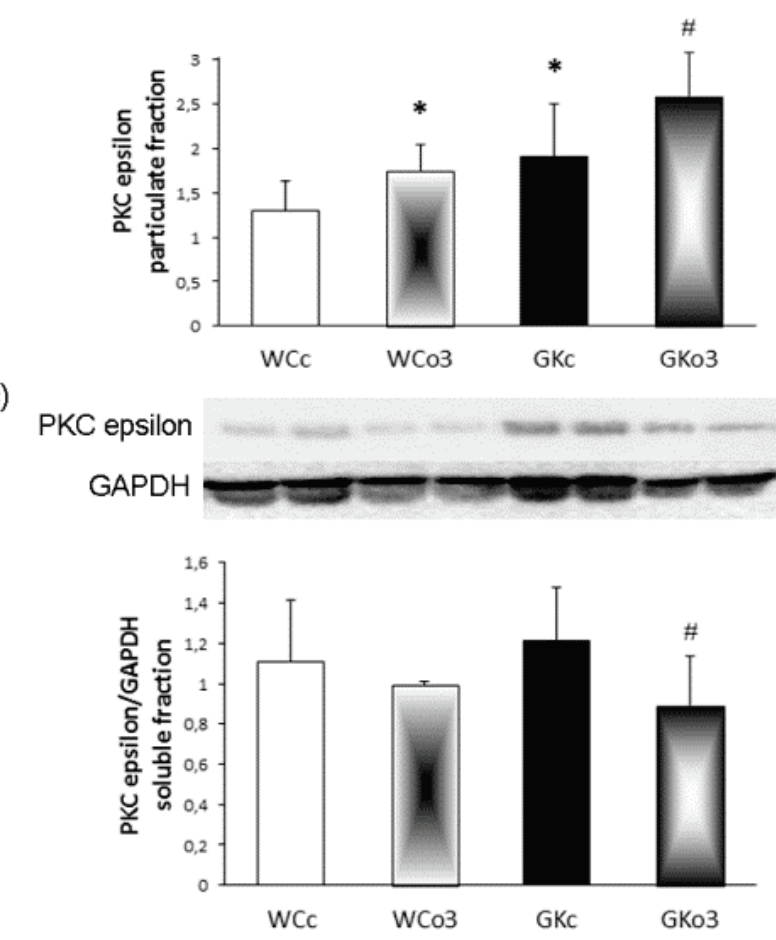

Fig. 6. Representative immunoblot and densitometric quantification of total protein kinase C (PKC)-epsilon expression (a) and its expression in particulate (b) and soluble (c) fractions normalized to GAPDH or actin in the left ventricles of untreated and omega-3-treated Wistar-Clea (WC) and Goto-Kakizaki (GK) rat hearts. WCC, untreated WC; WCo3, WC treated with omega-3; GKc, untreated GK; GKo3, GK treated with omega-3. The results are the mean \pm SD of 8 hearts per group. $* p<0.05$ compared with the WCc group, \# $p<0.05$ compared with the GKC group. 
(a)

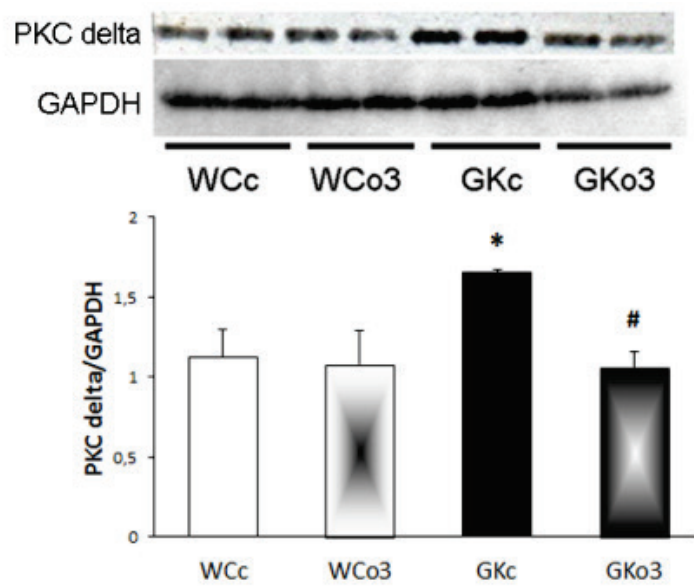

(b)

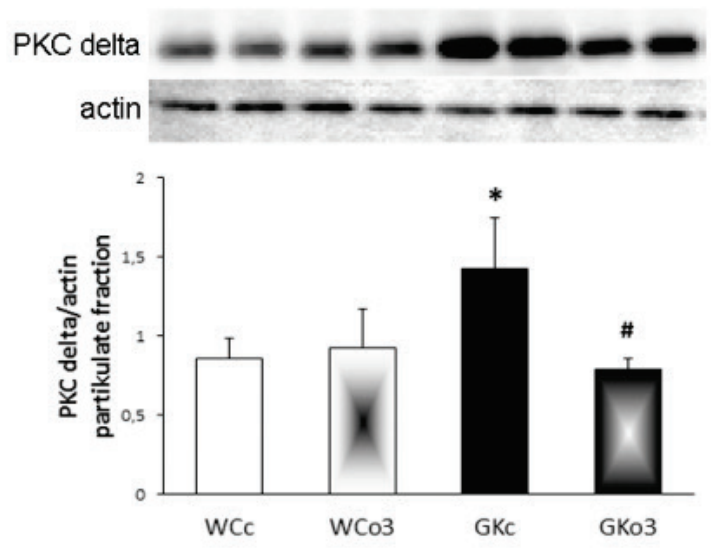

(c)
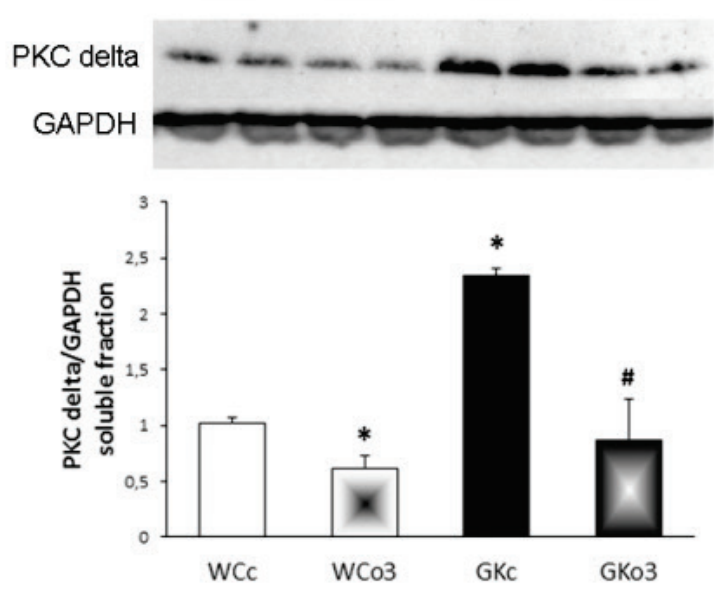

Fig. 7. Representative immunoblot and densitometric quantification of total protein kinase C (PKC)-delta expression (a) and its expression in particulate (b) and soluble (c) fraction normalized to GAPDH or actin in the left ventricles of untreated and omega-3 treated Wistar-Clea (WC) and Goto-Kakizaki (GK) rat hearts. WCC, untreated WC; WCO3, WC treated with omega-3; GKc, untreated GK; GKo3, GK treated with omega-3. The results are the mean \pm SD of 8 hearts per group. $* p<0.05$ compared with the WCc group, \# $\mathrm{p}<0.05$ compared with the GKc group.

\section{Discussion}

In the present study of Goto Kakizaki rats, a well-established T2DM model, we report several novel findings. Development of T2DM is associated with attenuation of myocardial $\mathrm{Cx} 43$ expression on both the transcriptional and protein levels. Functional phosphorylated forms of $\mathrm{Cx} 43$ are increased. However, the ratio of phosphorylated to non-phosphorylated forms of $\mathrm{Cx} 43$ as well as gap junction size are decreased. There are moderate focal alterations in the localization of $\mathrm{Cx} 43$ and integrity of cardiomyocytes and capillaries. T2DM upregulates myocardial $\mathrm{PKC} \varepsilon$ as well as $\mathrm{PKC} \delta$ and enhances their translocation to the membrane. Intake of omega-3 fatty acid ethyl esters results in upregulation of $\mathrm{Cx} 43$, increase of $\mathrm{PKC} \varepsilon$ and decrease of $\mathrm{PKC} \delta$ in particulate fractions as well as preservation of cardiomyocytes and capillary endothelial cells ultrastructure.

Consistent with others (Desrois et al. 2004), using this model of diabetes, the body, heart, and left ventricular weights of T2DM rats were significantly lower than those of non-diabetic rats. Decrease of these parameters has also been shown in T1DM (Lin et al. 2008, Howarth et al. 2008). As a complex endocrine and metabolic disorder, diabetes apparently contributes to growth retardation. Treatment with omega-3 did not affect these biometric parameters. During their prediabetic state (the first 4 weeks of life), GK rats have physiological levels of blood glucose despite some abnormalities in insulin secretion and peripheral insulin resistance (Movassat et al. 2007). We administered omega-3 from 5 weeks of life and observed a blood glucose reducing effect of $18.8 \%$ after 2 months of treatment. In addition, there was a mild but significant decrease in serum TAG and cholesterol, whereas the elevated activity of lysosomal NAGA persisted.

On examining the myocardial ultrastructure of diabetic rats at the end of the experiment (in 3-month-old animals), we found moderate disease-related changes. Notably, accumulation of glycogen, an increased number of ribosomes and longer gap junctions were present in the majority of well-preserved cardiomyocytes. Additionally, a minor population of cardiomyocytes exhibited ischemia-like injuries, such as intracellular and mitochondrial edema. Moreover, cardiomyocytes were connected by shorter gap junctions. However, internalization of this specific membrane structure (which precedes its degradation) was not enhanced at this stage of T2DM, in contrast to the hearts of rats with T1DM after 4 to 8 weeks (Lin et al. 2006, 2008). In addition, endothelial injury of some capillaries was detected, indicating impairment of their function. Omega-3 intake 
resulted in clear preservation of the integrity of cardiomyocyte mitochondria and cell membranes as well as capillaries. It appears that an improvement in myocardial ultrastructure is a characteristic feature of omega-3 treatment that has also been demonstrated in hereditary hypertriglyceridemic rats and SHR (Bacova et al. 2010, Radosinska et al. 2013). These findings suggest that increased incorporation of omega-3 (EPA and/or DHA) into cardiomyocyte and mitochondrial membranes most likely accounts for the protection of their integrity. Indeed, omega-3 intake has been shown to increase not only circulating EPA and/or DHA but also their content in red blood cells and cardiomyocytes (von Schacky and Harris 2007, Bačová et al. 2013). Furthermore, omega-3 intake attenuated the disordered pattern of $\mathrm{Cx} 43$ localization (lateralization) in T2DM and likewise abolished pronounced lateralization in hypertensionrelated cardiac hypertrophy (Radosinska et al. 2013). Treatment of diabetic rats with omega-3 also resulted in an increase of $\mathrm{Cx} 43$-positive gap junction size that was associated with upregulation of $\mathrm{Cx} 43 \mathrm{mRNA}$ and protein expression as well as with enhanced phosphorylation of Cx43. Nevertheless, early-stage T2DM was not associated with remarkable $\mathrm{Cx} 43$ remodeling, unlike acute or chronic T1DM (Zhukovska et al. 2014, Lin et al. 2006, 2008, Howarth et al. 2008).

In parallel to the increase in Cx43 mRNA, we observed a significant increase in total $\mathrm{Cx} 43$ protein in diabetic compared to non-diabetic rats and a further increase due to omega-3 intake in both groups. Furthermore, although the amounts of functional phosphorylated forms of $\mathrm{Cx} 43$ were increased, the ratio of phosphorylated to total $\mathrm{Cx} 43$ was reduced. This indicates that in T2DM the upregulation of $\mathrm{Cx} 43$ is accompanied by a defect in its phosphorylated status. This may explain, at least in part, why the size of gap junctions (known to be related to $\mathrm{Cx} 43$ phosphorylation) was decreased in GK rat hearts. Omega-3 improved the phosphorylated status and increased of the size of gap junctions.

Current studies suggest that enhanced phosphorylation of $\mathrm{Cx} 43$ in diabetic hearts can be mostly attributed to increased expression of PKC $\varepsilon$. Treatment with omega-3 enhanced the particulate fraction of PKC $\varepsilon$ indicating its possible contribution to attenuation of defects in phosphorylation status of myocardial $\mathrm{Cx} 43$ in T2DM. Nevertheless, the question remains as to how changes in myocardial $\mathrm{Cx} 43$ and $\mathrm{PKC} \varepsilon$ affect intercellular communication, arrhythmogenesis and heart function in non-treated as well as in omega- 3 treated T2DM rats.
Hyperglycemia has been reported to accelerate apoptosis in adult ventricular myocytes, which is associated with increased production of reactive oxygen species. Activation of $\mathrm{PKC} \delta$ is also involved in this process (Igarashi et al. 1999). In turn, the inhibition of PKC $\delta$ translocation to the membrane (i.e. its activity) increased the number of surviving cardiomyocytes exposed to hyperglycemia (Shizukuda et al. 2002). Whether activation of $\mathrm{PKC} \varepsilon$ and inhibition $\mathrm{PKC} \delta$ are related to cardioprotection attributed to omega-3 intake in T2DM should be explored in detail in further studies. Nevertheless, our findings are consistent with the proposed role of dietary fatty acids in cardiac cell death modulation in early diabetes (Ghosh and Rodrigues 2006) as well as in other cardiovascular diseases (Tribulova et al. 2015).

\section{Limitations}

The number of rats was insufficient to perform cardiac function analysis and susceptibility to arrhythmias in the Goto-Kakizaki diabetic rat hearts to determine whether modulation of $\mathrm{Cx} 43$ or PKC by omega-3 supplementation is relevant for improving functional parameters. A glucose tolerance test was not assessed to show further beneficial effects of omega-3 in this T2DM experimental model. Apart from protein kinase $\mathrm{C}$ other protein kinases that phosphorylate $\mathrm{Cx} 43$ (Yu et al. 2013, Benova et al. 2015) and related changes in myocardial conduction velocity should also be explored in further studies. Although our results demonstrate an association between myocardial $\mathrm{Cx} 43$ expression and omega-3 intake, they do not prove a direct causality between these variables. We also realize that comparison between T2DM and T1DM may be hypothetical, as genetic model versus an acquired model of DM are principally different.

\section{Conclusions}

The present results indicate that spontaneously diabetic GK rats at the early stage of disease exhibit increased expression of myocardial Cx43 accompanied by a decrease in its functional phosphorylated status and mild alterations in cellular $\mathrm{Cx} 43$ distribution. Diabetic rats benefit from omega-3 intake due to decrease of blood glucose, attenuation of myocardial $\mathrm{Cx} 43$ and gap junction alterations, as well as preservation of cardiomyocyte and capillary integrity. Our findings indicate that intake of 
omega-3 fatty acid ethyl esters in combination with antidiabetic drugs may also be beneficial for the management of type 2 diabetes mellitus in humans.

\section{Conflict of Interest}

There is no conflict of interest.

\section{Acknowledgements}

This study was supported by VEGA 2/0046/12, 1/0032/14, APVV-0348-12, 7AMB14SK123 and JSPS grants and by Research Project RVO: 67985823 (AV0Z 50110509). Omacor was kindly provided by Abbott Laboratories, Bratislava, Slovakia.

\section{References}

BACOVA B, RADOSINSKA J, KNEZL V, KOLENOVA L, WEISMANN P, NAVAROVA J, BARANCIK M, MITASIKOVA M, TRIBULOVA N: Omega-3 fatty acids and atorvastatin suppress ventricular fibrillation inducibility in hypertriglyceridemic rat hearts: implication of intracellular coupling protein, connexin-43. J Physiol Pharmacol 61: 717-723, 2010.

BAČOVÁ B, RADOŠINSKÁ J, VICZENCZOVÁ C, KNEZL V, DOSENKO V, BEÑOVA T, NAVAROVÁ J, GONÇALVESOVÁ E, VAN ROOYEN J, WEISMANN P, SLEZÁK J, TRIBULOVÁ N: Up-regulation of myocardial connexin-43 in spontaneously hypertensive rats fed red palm oil is most likely implicated in its anti-arrhythmic effects. Can J Physiol Pharmacol 90: 1235-1245, 2012.

BAČOVÁ B, SEČ P, RADOŠINSKÁ J, CERTÍK M, VACHULOVÁ A, TRIBULOVÁ N: Lower omega-3 index is a marker of increased propensity of hypertensive rat heart to malignant arrhythmias. Physiol Res 62: 201-208, 2013.

BENOVA T, KNEZL V, VICZENCZOVA C, BACOVA SJ, RADOSINSKA J, TRIBULOVA N: Acute antifibrillating and defibrillating potential of atorvastatin, melatonin, eicosapentaenoic acid and docosahexaenoic acid demonstrated in isolated heart model. $J$ Physiol Pharmacol 66: 83-89, 2015.

BERGERON R, YAO J, WOODS JW, ZYCBAND EI, LIU C, LI Z, ADAMS A, BERGER JP, ZHANG BB, MOLLER DE, DOEBBER TW: Peroxisome proliferator-activated receptor (PPAR)-alpha agonism prevents the onset of type 2 diabetes in Zucker diabetic fatty rats: A comparison with PPAR gamma agonism. Endocrinology 147: 4252-4562, 2006.

COTTIN SC, SANDERS TA, HALL WL: The differential effects of EPA and DHA on cardiovascular risk factors. Proc Nutr Soc 70: 215-231, 2011.

DECKELBAUM RJ, WORGALL TS, SEO T: N-3 fatty acids and gene expression. Am J Clin Nutr 83: 1520-1525, 2006.

DESROIS M, SIDELL RJ, GAUGUIER D, DAVEY CL, RADDA GK, CLARKE K: Gender differences in hypertrophy, insulin resistance and ischemic injury in the aging type 2 diabetic rat heart. $\mathrm{J} \mathrm{Mol} \mathrm{Cell} \mathrm{Cardiol}$ 37: 547-555, 2004.

FEDOR D, KELLEY DS: Prevention of insulin resistance by n-3 polyunsaturated fatty acids. Curr Opin Clin Nutr Metab Care 12: 138-146, 2009.

FONTES MS, VAN VEEN TA, DE BAKKER JM, VAN RIJEN HV: Functional consequences of abnormal Cx43 expression in the heart. Biochim Biophys Acta 1818: 2020-2029, 2012.

GHOSH S, RODRIGUES B: Cardiac cell death in early diabetes and its modulation by dietary fatty acids. Biochim Biophys Acta 1761: 1148-1162, 2006.

HOU L, LIAN K, YAO M, SHI Y, LU X, FANG L, HE T, JIANG L: Reduction of n-3 PUFAs, specifically DHA and EPA, and enhancement of peroxisomal beta-oxidation in type 2 diabetic rat heart. Cardiovasc Diabetol 11: 1-8, 2012.

HOWARTH FC, CHANDLER NJ, KHARCHE S, TELLEZ JO, GREENER ID, YAMANUSHI TT, BILLETER R, BOYETT MR, ZHANG H, DOBRZYNSKI H: Effects of streptozotocin-induced diabetes on connexin43 mRNA and protein expression in ventricular muscle. Mol Cell Biochem 319: 105-114, 2008.

IGARASHI M, WAKASAKI H, TAKAHARA N, ISHII H, JIANG ZY, YAMAUCHI T, KUBOKI K, MEIER M, RHODES CJ, KING GL: Glucose or diabetes activates p38 mitogen-activated protein kinase via different pathways. J Clin Invest 103: 185-195, 1999. 
JAYASHREE B, BIBIN YS, PRABHU D, SHANTHIRANI CS, GOKULAKRISHNAN K, LAKSHMI BS, MOHAN V, BALASUBRAMANYAM M: Increased circulatory levels of lipopolysaccharide (LPS) and zonulin signify novel biomarkers of proinflammation in patients with type 2 diabetes. Mol Cell Biochem 388: 203-210, 2014.

JULIEN J: Cardiac complications in non-insulin-dependent diabetes mellitus. J Diabetes Complications 11: 123-130, 1997.

KAZEMIAN P, KAZEMI-BAJESTANI SM, ALHERBISH A, STEED J, OUDIT GY: The use of $\omega$-3 poly-unsaturated fatty acids in heart failure: a preferential role in patients with diabetes. Cardiovasc Drugs Ther 26: 311-320, 2012.

KRAMER JH, MURTHI SB, WISE RM, MAK IT, WEGLICKI WB: Antioxidant and lysosomotropic properties of acute D-propranolol underlies its cardioprotection of postischemic hearts from moderate iron-overloaded rats. Exp Biol Med (Maywood) 231: 473-484, 2006.

LIN H, OGAWA K, IMANAGA I, TRIBULOVA N: Remodeling of connexin 43 in the diabetic rat heart. Mol Cell Biochem 290: 69-78, 2006.

LIN H, MITASIKOVA M, DLUGOSOVA K, OKRUHLICOVA L, IMANAGA I, OGAWA K, WEISMANN P, TRIBULOVA N: Thyroid hormones suppress epsilon-PKC signaling, down-regulate connexin-43 and increase lethal arrhythmia susceptibility in non-diabetic and diabetic rat hearts. J Physiol Pharmacol 59: 271-285, 2008.

MARCHIOLI R, MARFISI RM, BORRELLI G, CHIEFFO C, FRANZOSI MG, LEVANTESI G, MAGGIONI AP, NICOLOSI GL, SCARANO M, SILLETTA MG, SCHWEIGER C, TAVAZZI L, TOGNONI G: Efficacy of n-3 polyunsaturated fatty acids according to clinical characteristics of patients with recent myocardial infarction: insights from the GISSI-Prevenzione trial. J Cardiovasc Med 8: 34-37, 2007.

MÉZEŠOVÁ L, JENDRUCHOVÁ-JAVORKOVÁ V, VLKOVIČOVÁ J, OKRUHLICOVÁ L, FRIMMEL K, NAVAROVÁ J, KYSELOVÁ-BRNOLIAKOVÁ Z, VRBJAR N: Supplementation with n-3 polyunsaturated fatty acids to lipopolysaccharide-induced rats improved inflammation and functional properties of renal Na,K-ATPase. Nutr Res 33: 772-779, 2013.

MITASÍKOVÁ M, SMIDOVÁ S, MACSALIOVÁ A, KNEZL V, DLUGOSOVÁ K, OKRUHLICOVÁ L, WEISMANN P, TRIBULOVÁ N: Aged male and female spontaneously hypertensive rats benefit from n-3 polyunsaturated fatty acids supplementation. Physiol Res 57: 39-48, 2008.

MITASÍKOVÁ M, LIN H, SOUKUP T, IMANAGA I, TRIBULOVÁ N: Diabetes and thyroid hormones affect connexin-43 and PKC-epsilon expression in rat heart atria. Physiol Res 58: 211-217, 2009.

MOVASSAT J, CALDERARI S, FERNÁNDEZ E, MARTÍN MA, ESCRIVÁ F, PLACHOT C, GANGNERAU MN, SERRADAS P, ALVAREZ C, PORTHA B: Type 2 diabetes - a matter of failing beta-cell neogenesis? Clues from the GK rat model. Diabetes Obes Metab 9: 187-195, 2007.

POOLE CD, HALCOX JP, JENKINS-JONES S, CARR ES, SCHIFFLERS MG, RAY KK, CURRIE CJ: Omega-3 fatty acids and mortality outcome in patients with and without type 2 diabetes after myocardial infarction: a retrospective, matched-cohort study. Clin Ther 35: 40-51, 2013.

RADOSINSKA J, BACOVA B, KNEZL V, BENOVA T, ZURMANOVA J, SOUKUP T, ARNOSTOVA P, SLEZAK J, GONÇALVESOVA E, TRIBULOVA N: Dietary omega-3 fatty acids attenuate myocardial arrhythmogenic factors and propensity of the heart to lethal arrhythmias in a rodent model of human essential hypertension. J Hypertens 31: 1876-1885, 2013.

SEOK H, CHA BS: Refocusing peroxisome proliferator activated receptor- $\alpha$ : a new insight for therapeutic roles in diabetes. Diabetes Metab J 37: 326-332, 2013.

SERTOGLU E, KURT I, TAPAN S, UYANIK M, SERDAR MA, KAYADIBI H, EL-FAWAEIR S: Comparison of plasma and erythrocyte membrane fatty acid compositions in patients with end-stage renal disease and type 2 diabetes mellitus. Chem Phys Lipids 178: 11-17, 2014.

SHIMONI Y, LIU XF: Sex differences in the modulation of $\mathrm{K}^{+}$currents in diabetic rat cardiac myocytes. $J$ Physiol 550: 401-412, 2003.

SHIZUKUDA Y, REYLAND ME, BUTTRICK PM: Protein kinase C-delta modulates apoptosis induced by hyperglycemia in adult ventricular myocytes. Am J Physiol Heart Circ Physiol 282: H1625-H1634, 2002.

SOUKUP T: Effects of long-term thyroid hormone level alterations, n-3 polyunsaturated fatty acid supplementation and statin administration in rats. Physiol Res 63: 119-131, 2014. 
STILLWELL W, WASSALL SR: Docosahexaenoic acid: membrane properties of a unique fatty acid. Chem Phys Lipids 126: 1-27, 2003.

TRIBULOVÁ N, DUPONT E, SOUKUP T, OKRUHLICOVÁ L, SEVERS NJ: Sex differences in connexin-43 expression in left ventricles of aging rats. Physiol Res 54: 705-708, 2005.

TRIBULOVÁ N, KNEZL V, OKRUHLICOVÁ L, SLEZÁK J: Myocardial gap junctions: targets for novel approaches in the prevention of life-threatening cardiac arrhythmias. Physiol Res 57 (Suppl 2): S1-S13, 2008.

TRIBULOVÁ N, KNEZL V, SHAINBERG A, SEKI S, SOUKUP T: Thyroid hormones and cardiac arrhythmias. Vascul Pharmacol 52: 102-112, 2010.

TRIBULOVA N, SZEIFFOVA BACOVA B, BENOVA T, VICZENCZOVA C: Can we protect from malignant arrhythmias by modulation of cardiac cell-to-cellcoupling? J Electrocardiol 48: 434-440, 2015.

VILLARROYA J, FLACHS P, REDONDO-ANGULO I, GIRALT M, MEDRIKOVA D, VILLARROYA F, KOPECKY J, PLANAVILA A: Fibroblast growth factor-21 and the beneficial effects of long-chain n-3 polyunsaturated fatty acids. Lipids 49: 1081-1089, 2014.

VON SCHACKY C, HARRIS WS: Cardiovascular risk and the omega-3 index. J Cardiovasc Med 8: 46-49, 2007.

WANG YW, SUN GD, SUN J, LIU SJ, WANG J, XU XH, MIAO LN: Spontaneous type 2 diabetic rodent models. J Diabetes Res 2013: 1-8, 2013.

YU L, ZHAO Y, XU S, DING F, JIN C, FU G, WENG S: Advanced glycation end product (AGE)-AGE receptor (RAGE) system upregulated connexin43 expression in rat cardiomyocytes via PKC and Erk MAPK pathways. Int J Mol Sci 14: 2242-2257, 2013.

ZÁLEŠÁK M, BLAŽÍČEK P, GABLOVSKÝ I, LEDVÉNYIOVÁ V, BARTEKOVÁ M, ZIEGELHÖFFER A, RAVINGEROVÁ T: Impaired PI3K/Akt signaling as a potential cause of failure to precondition rat hearts under conditions of simulated hyperglycemia. Physiol Res 64: 633-641, 2015.

ZHUKOVSKA A, SHYSH A, BACOVA B, RADOSINSKA J, BENOVA T, VICZENCZOVA C, DOSENKO V, MOIBENKO O, TRIBULOVA N: Heart-protective effect of n-3 PUFA demonstrated in a rat model of diabetic cardiomyopathy. Mol Cell Biochem 389: 219-227, 2014.

ZULIANI G, GALVANI M, LEITERSDORF E, VOLPATO S, CAVALIERI M, FELLIN R: The role of polyunsaturated fatty acids (PUFA) in the treatment of dyslipidemias. Curr Pharm Des 15: 4087-4093, 2009. 